\title{
Exteriority of Holstein Cattle of Various Origins in the Conditions of the Tyumen Region
}

\section{Marina Svyazhenina}

Department of Livestock Production and Processing Technology, Federal State Budgetary Educational Institution of the North Urals, Tyumen, Russia

\section{Abstract}

The modern production of animal products depends largely on the quality of animals. Dairy farming is most often based on the use of Holstein cows as one of the most adapted to industrial conditions[1]. The Tyumen Oblast has been importing the cattle of this breed since 2006, and it was imported from different European countries, as well as was obtained as a result of the absorption crossbreeding of cows of the domestic black-motley breed [2--4]. Since the productivity of animals to a large extent depends not only on the origin, but also on the external qualities of animals, a study of the

Corresponding Author:

Marina Svyazhenina

marin968@inbox.ru

Received: 25 October 2019

Accepted: 15 November 2019

Published: 25 November 2019

Publishing services provided by Knowledge E

(c) Marina Svyazhenina. This article is distributed under the terms of the

Attribution License, which permits unrestricted use and redistribution provided that the original author and source are credited.

Selection and Peer-review under the responsibility of the AgroSMART 2019 Conference Committee. exteriors of the first exteriors of the Korovogolshtin breed was carried out. In the course of the study, it was found that both the origin and the "farm" factor were influenced by the exterior quality of the animals. Moreover, the influence of the "farm" factor was greater than the origin of cows. The cows of their own breeding, obtained as a result of absorption crossbreeding, did not differ significantly from the imported cows by the majority of external indicators. This allows us to conclude that the imports may be replaced by our own reproduction, including the use of absorption crossbreeding of black and motley and Holstein cattle.

Keywords: exterior, dairy cattle breeding, Holstein breed, origin.

\section{Introduction}

The need for exteriors' assessment and evaluation is the first step in the process of existence, although it is indirect, but quite significant in terms of the relationship between the productivity of animals and their suitability for industrial use [5--7]. Availability of technological chains in production requires standard animals, similar not only to productive qualities, but also to exterior indicators. Such a similarity in a significant measure is characterized by the Holstein breed, which has become widespread throughout the world $[8,9]$. There are some differences between breeding programs and animal selection criteria in each country of breeding. Therefore, the Holstein animals imported to the Tyumen region from some European countries were characterized by some external differences [10]. In addition, as the producers of this breed have been used to 
improve the black-and-marsh cattle of their own breeding for a long time, in some farms there appeared groups of cows with a share of blood on the Holstein breed of more than $96 \%$, which indicates the emergence of cattle of Holstein breed already their own selection [11-13]. Such breeding, both cacsoo-technical and economic point of view is more rational. In this connection, the aim was to study the peculiarities of exteriors of different origins and to show the possibility of obtaining high-quality animals of their own breeding on the basis of more adapted black-and-pearl cattle.

\section{Research Methods}

Studies were conducted in the tribal farms of the Tyumen region. For the analysis, the data of breeding records of three farms, including the breeding plant -- CJSC "Poultry farm "Borovskaya" were used. The level of feeding in the farms did not differ significantly and corresponded to the productive indices of animals. The object of the research was the animals of different origin: Dutch selection (HS, n=116), German selection (NS, $n=86$ ), obtained as a result of the absorption of black-and-peasty cattle of domestic selection (OS, $n=20$ ). The exteriors were evaluated by periods, body indexes and linear methods [14].

\section{Results}

According to the method of assessment of animals for distinctiveness, uniformity and stability [15] the following parameters of measurements are recommended for the selection of Holstein cows of the first lactation breed: height in the withers $136 \mathrm{~cm}$, height in the sacrum $140 \mathrm{~cm}$, oblique length of the body $-153 \mathrm{~cm}$, breast depth - $73 \mathrm{~cm}$, breast width -- $47 \mathrm{~cm}$, breast circumference $195 \mathrm{~cm}$, width in mackerel -$53 \mathrm{~cm}$, circumference of the pelvis -- 18--20 cm. When comparing the recommended measurements with the results of studies for most of them, the following observations were observed for certain groups of animals.

However, some deviations were also revealed: a large body length, the difference was $5.3--17.7 \mathrm{~cm}(+3.5 \ldots+11.6 \%$ of the desired figure), a smaller breast width by 3.8--6.2 cm (--8.1...--13.2 \%); cows of tribal loudspeakers had a smaller breast depth of 3.4--4.8 cm (--2.5...--6.6 \%) and a width of 3.3--3.5 cm (--6.2...--6.6 \%). That is, in the conditions of tribal loudspeakers, regardless of the country of origin, the cows of the first lactation had a slightly less developed depth and width of the chest. 
The following values are considered to be optimal for Holstein cattle by body composition indices: long legs index -- $46.3 \%$, stretch -- $112.5 \%$, pelvic thoracic -- 88.7 \%, thoracic -- $64.4 \%$, blockiness -- $127.5 \%$, overgrowth -- $102.9 \%$, bones --13.2...$14.7 \%$. Representatives of different groups had longer legs $+0.3 \ldots+6.6 \%$, trunk sprawl $+3.7 \ldots+10.0 \%$, overgrowth $+0.1 \ldots+2.7 \%$ in comparison with the optimal one. The indices of other indices are less than the recommended ones: pelvic thoracic index by 3.0-$12.4 \%$, thoracic index by $1.9--8.7 \%$, blockiness index by $5.1-10.3 \%$. Bone index of all groups was within the normal development limits. Consequently, Holstein animals were characterized by some late maturation, as the revealed peculiarities of the physique indicate the following development of cows of the first lactation.

The animals in the groups are quite homogeneous, as the differences between the representatives of the same origin, kept in different farms, in most cases are unreliable. Therefore, it is possible to compare representatives of different origins (without taking into account the economic affiliation) with the recommended intervals [15] for Holstein cattle. The following was found. Cows of domestic selection mainly exceeded the standard values, but only in terms of width and depth of breasts were lower than the recommended values by 2.1 and $10.2 \%$, respectively. The animals of the Dutch selection had a sufficient width of the buttock in mackerel (only --1.3\%) and a strong skeleton, but the smallest among all groups of breast widths $(87.9 \%$ of the optimal one) in accordance with their height, length and depth of body. Cows of the German selection had smaller measurements among all groups, except for the breast width, where the obtained results were the best among all cows and were only $9.4 \%$ less than the recommended ones.

A similar analysis of the cow body indexes of different origins in the combined groups revealed a rather harmonious body of German breeding cows, which are closest to the optimal development of dairy cattle, with variations in the indexes ranging from --3.6 $\%$ for the straddle index to $+7.4 \%$ for the Long-leggedness index. The Dutch female breeders had low breast and pelvic indices, which were $11.5 \%$ and $11.0 \%$ lower than the recommended ones, respectively. At the same time, animals had the highest rates of overgrowth $+1.4 \%$ and bone $+2.4 \%$. Such peculiarities of development are usually typical for animals that have not yet completed their growth: Holstein cattle of domestic breeding are peculiar in their body composition, they have: long legs $(+4.1 \%)$, body stretch (+5.1\%), narrow chest (--8.4\% chest index), body enlargement to the back (--12.4 $\%$ of pelvic chest index), in the absence of undesirable overgrowth and relatively thin skeleton. Consequently, the cows of their own breeding were quite early maturing and tilted slightly towards tenderness, with a pronounced upper milk triangle. 
The method of linear assessment of the exterior of animals was originally developed to characterize the animals of Holsteiner breed and modern selection of this cattle is not carried out without the use of this assessment. This is due to the need to obtain properly developed animals that are able to have high productivity for a longer time.

Comparison of the representatives of the breeding plant and the tribal loudspeakers showed that according to the signs of system $A$, the animals of the breeding plant had a big growth, a long sacrum and a slightly whistling ass. No clear differences were found for the other indicators. This homogeneity is also proved by relatively low variation coefficients, most of which were within the range of up to $30 \%$, which is considered normal for a homogeneous herd in the linear evaluation of system $A$.

TABLE 1: Linear assessment of cows of the first lactation of different origin (system A), score.

Indicator
Growth
Body depth
Body strength
Dairy forms
Sacrum length
Pelvic position
Pelvic width
Muscularity
Positioning the hind legs (side
view)
Hoof angle
Attachment of front lobes
Udder frontal lobes length
Rear fraction mounting height
Rear fraction width
Udder
Udder bottom position
Location of front nipples
Nipple length

\begin{tabular}{|c|c|c|c|c|c|}
\hline \multicolumn{2}{|c|}{ CJSC P/f Borovskaya } & \multicolumn{2}{|c|}{ SPK Tavolzhan } & \multicolumn{2}{|c|}{ Zauralye LLC } \\
\hline$C C(n=20)$ & $\Gamma C(n=20)$ & $\mathrm{HC}(\mathrm{n}=98)$ & $\Gamma C(n=80)$ & $\mathrm{HC}(\mathrm{n}=46)$ & $\Gamma \mathrm{C}(\mathrm{n}=48)$ \\
\hline $7.1 \pm 0.2$ & $7.1 \pm 0,2$ & $6.5 \pm 0,2$ & $6.7 \pm 0,2$ & $6.5 \pm 0.2$ & $6,5 \pm 0.2$ \\
\hline $4.7 \pm 0.5$ & $4.7 \pm 0,5$ & $3.5 \pm 0,2$ & $4.9 \pm 0,2$ & $4.5 \pm 0.2$ & $4,3 \pm 0.1$ \\
\hline $3.4 \pm 0.4$ & $3.4 \pm 0,4$ & $3.9 \pm 0,1$ & $4.8 \pm 0,1$ & $4.0 \pm 0.1$ & $3,6 \pm 0.1$ \\
\hline $6.5 \pm 0.7$ & $6.5 \pm 0,7$ & $6.0 \pm 0,2$ & $5.5 \pm 0,1$ & $6.3 \pm 0.2$ & $6,2 \pm 0.1$ \\
\hline $5.1 \pm 0.3$ & $5.1 \pm 0,3$ & $4.3 \pm 0,2$ & $5.0 \pm 0,2$ & $4.5 \pm 0.2$ & $4,8 \pm 0.1$ \\
\hline $5.4 \pm 0.2$ & $5.4 \pm 0,2$ & $4.8 \pm 0,2$ & $5.2 \pm 0,1$ & $5.1 \pm 0.3$ & $5,2 \pm 0.2$ \\
\hline $3.6 \pm 0.4$ & $3.6 \pm 0,4$ & $2.9 \pm 0,2$ & $3.9 \pm 0,2$ & $3.1 \pm 0,2$ & $4,2 \pm 0.1$ \\
\hline $4.6 \pm 0.4$ & $4.6 \pm 0,4$ & $4.6 \pm 0,1$ & $4.8 \pm 0,1$ & $4.7 \pm 0.1$ & $3,9 \pm 0.1$ \\
\hline $4.6 \pm 0.2$ & $4.6 \pm 0,2$ & $5.2 \pm 0,1$ & $5.4 \pm 0,1$ & $5.1 \pm 0.1$ & $4,8 \pm 0.1$ \\
\hline $4.3 \pm 0.3$ & $4.3 \pm 0,3$ & $4.3 \pm 0,2$ & $4.1 \pm 0,1$ & $4.4 \pm 0.2$ & $4,1 \pm 0.1$ \\
\hline $6.4 \pm 0.4$ & $6.4 \pm 0,4$ & $6.0 \pm 0,2$ & $5.4 \pm 0,2$ & $5.8 \pm 0.3$ & $5,2 \pm 0.2$ \\
\hline $6.1 \pm 0.3$ & $6.1 \pm 0,3$ & $6.8 \pm 0,5$ & $5.8 \pm 0,2$ & $6.5 \pm 0.4$ & $5,1 \pm 0.2$ \\
\hline $5.2 \pm 0.5$ & $5.2 \pm 0,5$ & $6.5 \pm 0,3$ & $6.0 \pm 0,2$ & $6.7 \pm 0.2$ & $7,2 \pm 0.2$ \\
\hline $6.4 \pm 0.3$ & $6.4 \pm 0,3$ & $7.0 \pm 0,2$ & $6.8 \pm 0,2$ & $6.7 \pm 0.2$ & $6,1 \pm 0.3$ \\
\hline $5.0 \pm 0.5$ & $5.0 \pm 0,5$ & $5.5 \pm 0,2$ & $5.4 \pm 0,1$ & $5.6 \pm 0.2$ & $5,1 \pm 0.2$ \\
\hline $6.7 \pm 0.2$ & $6.7 \pm 0,2$ & $6.5 \pm 0,2$ & $6.5 \pm 0,2$ & $6.4 \pm 0.2$ & $6,8 \pm 0.1$ \\
\hline $5.7 \pm 0.3$ & $5.7 \pm 0,3$ & $7.2 \pm 0,2$ & $6.7 \pm 0,2$ & $7.0 \pm 0.3$ & $6,9 \pm 0.1$ \\
\hline $4.8 \pm 0.2$ & $4.8 \pm 0,2$ & $4.4 \pm 0,2$ & $5.0 \pm 0,1$ & $4.4 \pm 0.1$ & $4,3 \pm 0.1$ \\
\hline
\end{tabular}

Further assessment of the exterior of Holstein animals depending on their origin allows us to identify more clearly their exterior differences. Thus, cows of domestic selection were characterized by high growth ( +2.1 points from the optimal 5 points), narrow thoracic bone (--1.6 points), pronounced dairy forms (+1.5 points). As for the 
development of the problem, they had a narrowness (--1.4 points). Legs were normal, hooves with a slightly sharp angle of inclination (--0.7 points). The udder in animals was tightly attached (+1.4 points), with long anterior lobes (+1.1 points), and the hind lobes were wide ( +1.4 points). Udder location above ground is high $(+1.7$ points), glandular tissue is well developed. Nipples sufficient in length (--0.2 points), front ones slightly close (+0.7 points).

Cows of Dutch selection also had high growth ( +1.7 points), among all groups had the best body depth (--0.2 points) and strength (--0.7 points), milk forms were expressed well (+1.1 points). Animals' butt was optimal in length, but narrow (--1.0 points). The muscularity of the cows in this group was only slightly lower than that of their own selection (--0.6 points). Rear extremities with island hooves (--0.9 points). The udder was characterized by sufficiently long ( +0.6 points) and densely attached ( +0.4 points) anterior lobes. Rear udder lobes are highly suspended (+1.5 points). The udder is located high above the ground ( +1.6 points), as well as the udder of its own selection, and the front nipples are close $(+1.6$ points).

Animals of German selection among all groups had a smaller growth (above 5 points by 1.5 points), insufficient body depth (--1.2 points). At the same time, they have a relatively wide thoracic bone (--1.1 points) and well-developed milk forms (+1.1 points). Back was slightly short (--0.6 points) and narrow (--2.0 points). The udder was tightly attached (+0.9 points) with rather long anterior lobes ( +1.7 points), while the posterior lobes were very wide ( +1.9 points), with high attachment ( +1.6 points), and the udder bottom was high (+1.5 points). Front nipples are shortened (--0.6 points) with narrow placement (+2.1 points).

In spite of the differences in the A-score system between women from different breeding groups, it should be noted that cows of all groups were mostly well developed, with the majority of external characteristics within the range of 4--6 points, which is allowed by the variation of the assessed characteristics.

System B allows to set a complex exterior class, which indicates, among other things, the tribal value of animals. System B exteriors are shown in Table 2.

When comparing the indices of the breeding plant and tribal loudspeakers at once revealed reliably higher evaluation scores at the first $(P>0,999)$, only on the basis of "leg" difference is insignificant. Differences between the representatives of own and Dutch selection in the conditions of the plant are also reliable +1.7...+3.9 points in favor of imported livestock ( $>$ > 0.95--0.99), again, except for the sign of "leg".

The revealed peculiarities of exterior formation in representatives of different origins are connected with the fact that cows of their own selection are well adapted to local 
TABLE 2: Linear assessment of cows of different origins (system B), score.

Indicators
Body size
Milk signs
Legs
Udder
General view
Comprehensive
assessment

\begin{tabular}{|c|c|}
\hline CJSC P/f Borovskaya \\
\hline$C C(n=20)$ & $\Gamma C(n=20)$ \\
\hline $80.8 \pm 0.5$ & $82.8 \pm 0.5$ \\
\hline $81.0 \pm 1.1$ & $84.9 \pm 0.2$ \\
\hline $78.0 \pm 1.6$ & $79.6 \pm 0.7$ \\
\hline $81.1 \pm 0.5$ & $83.3 \pm 0.5$ \\
\hline $80.1 \pm 0.4$ & $81.8 \pm 0.5$ \\
\hline $80.1 \pm 0.5$ & $82.6 \pm 0.4$ \\
\hline
\end{tabular}

\begin{tabular}{|c|c|}
\hline \multicolumn{2}{|c|}{ SPK Tavolzhan } \\
\hline $\mathrm{HC}(\mathrm{n}=98)$ & $\Gamma \mathrm{C}(\mathrm{n}=80)$ \\
\hline $78.4 \pm 0.2$ & $78.8 \pm 0.2$ \\
\hline $78.8 \pm 0.2$ & $79.2 \pm 0.2$ \\
\hline $77.6 \pm 0.3$ & $76.5 \pm 0.4$ \\
\hline $78.8 \pm 0.4$ & $78.1 \pm 0.3$ \\
\hline $77.9 \pm 0.2$ & $77.7 \pm 0.2$ \\
\hline $78.4 \pm 0.2$ & $78.1 \pm 0.2$ \\
\hline
\end{tabular}

\begin{tabular}{|c|c|}
\hline \multicolumn{2}{|c|}{ Zauralye LLC } \\
\hline $\mathrm{HC}(\mathrm{n}=46)$ & $\Gamma \mathrm{C}(\mathrm{n}=48)$ \\
\hline $78.0 \pm 0.2$ & $78.6 \pm 0.3$ \\
\hline $78.6 \pm 0.2$ & $79.7 \pm 0.3$ \\
\hline $77.6 \pm 0.3$ & $78.3 \pm 0.3$ \\
\hline $77.8 \pm 0.4$ & $78.7 \pm 0.3$ \\
\hline $77.6 \pm 0.2$ & $78.7 \pm 0.3$ \\
\hline $77.9 \pm 0.2$ & $78.1 \pm 0.7$ \\
\hline
\end{tabular}

conditions and are characterized by early maturation. Cows of Dutch selection, having a very high growth rate, have managed to form better, and even having got into new conditions, were able to demonstrate good indicators of development. Livestock of German origin have been growing for a little longer, so adaptation to the new conditions has led not only to a decrease in the intensity of growth, but also to a decrease in the rate of external evaluation.

\section{Discussion}

The results indicate a relative homogeneity of Holsteiner cattle in terms of their exteriors, regardless of origin. The presence of some peculiarities of different populations of this breed of cattle is explained by the peculiarities of breeding in importing countries. Thus, in the Netherlands, breeding is carried out at a high rate of maturation of animals, which, among other things, leads to the acquisition of animals that gradually deviate to the tender type of constitution, because it is the representatives of this type of livestock in the most favorable conditions of breeding are characterized by a high rate of growth. In Germany, one of the signs of selection is the sufficient strength of the constitution -this in turn forms a herd, somewhat inferior in maturity to the Dutch animals, but less whimsical and practical in use. The number of livestock of domestic selection on the main external indicators almost does not differ from the imported cattle and to a greater extent its exterior depends on what quality bulls will be used by producers. 


\section{Conclusion}

In the course of the research it was found out that Holstein cattle of domestic breeding are not inferior in their external characteristics to the animals imported from Europe. The local black-motley cattle is a mother's newborn population, and the obtained animals have additional possibilities of adaptation to the climatic conditions of the region.

Creation of a tribal base of fresh animals of own breeding is a priority task, which increases the economic efficiency of dairy cattle breeding.

\section{Financing}

The work was carried out in accordance with the subject "Development of a system of measures for adaptation of highly productive and user-friendly cattle imported to the territory of the Russian Federation from foreign countries", State Registration No. 01200953129.

\section{Confirmation}

The author thanks his colleagues for their contributions in support of the research.

\section{Conflict of Interest}

The author has no conflict of interest.

\section{References}

[1] Chasovshchikova, M.A., Sheveleva, O.M. (2017). Duration of economic use and lifetime productivity of cows of Dutch origin of different generations. Bulletin of Altai State Agrarian University, no. 12(158), pp. 104--108.

[2] Paronyan, I.A. (2018). Possibilities to preserve and improve the gene pool of cattle breeds of domestic selection, vol. 32, no. 5, pp. 63--66.

[3] Chasovshchikova, M.A., Sheveleva, O.M., Svjazhenina, M.A., Tatarkina, N.I., Satkeeva, A.B. (2017). Relationship between the genetic variants of kappa-casein and prolactin and the productive-biological characteristics of cows of the blackmotley breed. Journal of Pharmaceutical Sciences and Research, vol. 9, no. 7, pp. 1038--1044. 
[4] Chasovshchikova, M.A., Svyazhenina, M.A., Sheveleva, O.M. (2015). Selection and biological peculiarities of black and motley cattle of the Tyumen region. Chief zootechnician, no. 5-6, pp. 16--22.

[5] Sheveleva, O.M., Svyazhenina, M.A., Chasovshchikova, M.A. (2012). Livestock exterminator of different origin. The Siberian Bulletin of Agricultural Science, no. 5(228), pp. 42--46.

[6] Sheveleva, O.M. (2006). Dairy productivity and external features of cattle of blackmotley breed and its mixtures with Holstein in the conditions of Northern Trans-Urals, no. 10, pp. 178--182.

[7] Danilkiv, O.N., Siratsky, I.Z. (2001). Curvilinity of the relationship between the level of cows' milk yield and the external characteristics. Zootechniya, no. 9, pp. 2--3.

[8] Yeghiazaryan, A., Nebasova, N. (2009). Assessment of cow's exterior and service life. Animal husbandry in Russia, no. 10, pp. 49--52.

[9] Servakh, B. (2011). Optimal indicators of exterior traits. Animal husbandry in Russia, no. 5 , pp. 35--40.

[10] Belenkaya, A.E. (2017). Productive and reproductive qualities of Holstein cattle in the Northern Trans-Urals. Agrifood policy of Russia, no. 12(72), pp. 72--74.

[11] Dunin, I., Kochetkov, A., Sharkaev, V. (2011). Main characteristics of dairy cattle breeding in the Russian Federation. Dairy and beef cattle breeding, no. 7, pp. 2-4 .

[12] Kostomakhin, N.M. (2008). Adaptive capacity and productive qualities of Holstein cattle. Main zootechnician, no. 1, pp. 15--22.

[13] Mymrin, V. (2012). Characteristics of the state of the population of black-and-motley cattle of the Ural type. Dairy and beef cattle breeding, no. S1, pp. 22--24.

[14] VNIIplem. (1998). Collection of normative documents for the evaluation of pedigree material SNPlem P10--96. Rules for the evaluation of the structure of daughters of bulls-producers of dairy and meat breeds, vol. 1, p. 232.

[15] VNIIplem. (1997). Collection of legal and regulatory acts to the federal law "On breeding achievements". Methods of carrying out tests for distinctiveness, homogeneity and stability of cattle, p. 204. 